\title{
Análise das condições favoráveis à formação de bolor em edificação histórica de Pelotas, RS, Brasil
}

Analysis of the favorable conditions for mold formation in historical building of Pelotas, RS, Brazil

\section{Fernanda Lamego Guerra \\ Eduardo Grala da Cunha \\ Antônio César Silveira Baptista da Silva Stífany Knop}

\section{Resumo}

Fernanda Lamego Guerra

Faculdade de Arquitetura e Urbanismo

Universidade Federal de Pelotas Rua Benjamim Constant, 1359, Centro, Campus Porto Pelotas - RS - Brasi CEP 96010-020 Tel.: (53) 81050111 E-mail: flamg29@yahoo.com.br

Eduardo Grala da Cunha Faculdade de Arquitetura e Urbanismo

Universidade Federal de Pelotas Tel.: (53) 3284-5500 Ramal 5503 E-mail: eduardo.grala@ufpel.edu.br

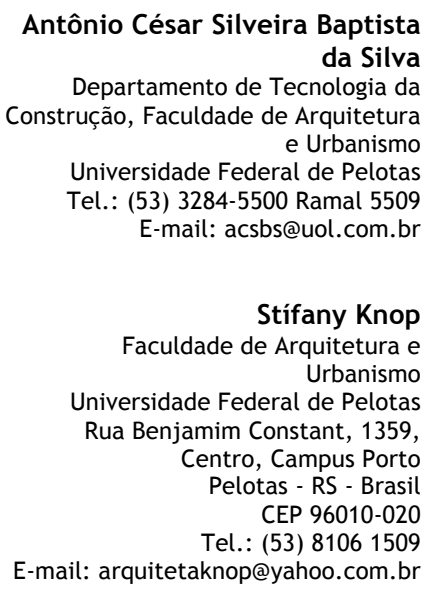
da Silva

Departamento de Tecnologia da Construção, Faculdade de Arquitetura e Urbanismo

Universidade Federal de Pelotas Tel.: (53) 3284-5500 Ramal 5509 E-mail: acsbs@uol.com.br

Stífany Knop Faculdade de Arquitetura e Urbanismo

Universidade Federal de Pelotas Rua Benjamim Constant, 1359, Centro, Campus Porto Pelotas - RS - Brasil CEP 96010-020

Tel.: (53) 81061509 E-mail: arquitetaknop@yahoo.com.br

Recebido em 30/06/12 Aceito em 06/12/12

\section{Abstract}

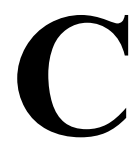

onsiderando a relevância do desenvolvimento de estudos que visam a compreender as condições ambientais favoráveis à formação do bolor, este artigo apresenta uma análise do desempenho da superfície interior de uma parede voltada ao exterior em uma edificação histórica na cidade de Pelotas, RS. A superfície selecionada apresentava formação de bolor, confirmada por uma análise microbiológica. Com o objetivo de compreender as condições ambientais que favoreceram a formação do bolor na superfície naquele ambiente, foram aplicados dois métodos de análise das condições higrotérmicas da superfície: o primeiro considera o regime de transferência de calor estacionário; e o segundo, por simulação computacional, considera o regime de transferência de calor transiente. Os resultados obtidos confirmaram a possibilidade da formação de bolor, levando em conta, principalmente, os aspectos de umidade próxima à superfície da parede e temperatura superficial interna. Para o desenvolvimento desta análise foram consideradas as observações das normas brasileiras NBR 15220: desempenho térmico de edificações: parte 2 (ABNT, 2005), da NBR 15575: edificações habitacionais de até cinco pavimentos (ABNT, 2008b) e da norma alemã DIN 4108-3: isolamento térmico e economia de energia em edifícios (2001).

Palavras-chave: Bolor. Edificações históricas. Transmitância térmica.

Considering the importance of developing studies that comprehend the favorable environmental conditions to mold formation, this paper presents an analysis of the inner surface of one outside facing wall in an selected space of a historic building in the city of Pelotas, RS. The analyzed surface presents mold occurrence, confirmed with microbiological analyses. In order to understand the environmental conditions that further the formation of mold on this surface, two distinct methods of hygrothermal conditions at the surface were analyzed: the first one considers steady-state heat transfer; and the second one, via computer simulation, considers transient heat transfer. Results, from both methods, confirmed the mold formation possibility, particularly accounting for issues related to moisture next to wall surface as well as inner surface temperature. Analyses were accomplished in view of NBR 15220-2: thermal performance of buildings: part 2 (ABNT, 2005), NBR 15575-1: dwellings up to five floors (ABNT, 2008) and the German standard DIN 4108-3: thermal insulation and energy saving in buildings (2001).

Keywords: Mold. Historic buildings. Thermal transmittance. 


\section{Introdução}

Pelotas, cidade localizada no extremo sul do Rio Grande do Sul, caracteriza-se por apresentar um clima temperado subtropical úmido, com temperaturas médias anuais de $17,6{ }^{\circ} \mathrm{C}$ e umidade relativa do ar em torno dos $80,7 \%$. A média das temperaturas mínimas anuais é de $13,8^{\circ} \mathrm{C}$, e a média das temperaturas máximas é de $22,9{ }^{\circ} \mathrm{C}$, de acordo com as Normais Climatológicas, período 1971-2000 (EMPRESA..., 2011). Conforme a NBR 15220-3 (ABNT, 2005): desempenho térmico de edificações: parte 3: zoneamento bioclimático brasileiro, Pelotas está localizada na zona bioclimática 2 .

O município possui um rico acervo patrimonial edificado reconhecido nacionalmente, caracterizado por construções principalmente do século XIX. Tal acervo é valorizado por fazer parte de um contexto histórico que remete a um período bastante próspero $\mathrm{e}$ de rápido desenvolvimento do município. Estão catalogados na Secretaria Municipal de Cultura cerca de 1.200 prédios inventariados, 11 tombados em âmbito municipal, 1 em âmbito estadual e 4 tombamentos em âmbito federal, pelo Instituto do Patrimônio Histórico e Artístico Nacional (Iphan). Muitas dessas edificações recebem medidas constantes de intervenção visando ao restabelecimento de sua integridade física. Contudo, o problema relacionado ao surgimento do bolor demonstra-se intermitente.

Na prática, em edificações convencionais, busca-se resolver a problemática do aparecimento desse fenômeno com a aplicação de fungicidas ou tintas especiais com microbiocidas, contudo não se elimina a causa do problema, além do que se sabe que tais produtos apresentam um limitado tempo de ação. Ademais, em se tratando de edificações históricas, foco deste estudo, o problema do bolor torna-se mais grave pela impossibilidade de aplicação de produtos que sejam incompatíveis com o material original. Muitas vezes, as soluções adotadas demonstram-se pouco eficazes, reincindindo em curto espaço de tempo, o que enfatiza a importância da compreensão das condições que favorecem sua proliferação, buscando, com isso, medidas preventivas a seu aparecimento.

O bolor, que se desenvolve nas superfícies das paredes das edificações, manifesta-se através da ação de micro-organismos conhecidos como fungos filamentosos. Estes são micro-organismos aeróbios e decompositores da matéria orgânica. Para Caneva, Nugari e Salvadori (2000), mesmo nos casos das superfícies de composição inorgânica, a disponibilidade de resíduos orgânicos de diferentes naturezas é bastante comum, o que permite o crescimento de diversas espécies de fungos que possuam poucas exigências nutricionais.

Sedlbauer (2001) afirma que a associação de condições ideais de temperatura e umidade à disponibilidade de nutrientes, além de outros fatores como o pH ideal, torna favorável a incidência de manifestações patológicas relacionadas aos fungos filamentosos.

O presente estudo pretende, mediante análise de uma superfície interna de uma edificação histórica na cidade de Pelotas, RS, compreender as condições ambientais que favorecem a formação de bolor na superfície desse ambiente por meio da aplicação de dois métodos de análise das condições higrotérmicas da superfície: o primeiro considerando o regime de transferência de calor estacionário; e o segundo, por simulação computacional, considerando o regime de transferência de calor transiente. Este estudo pode auxiliar na compreensão dos fatores envolvidos no problema relacionado aos fungos filamentosos nas edificações históricas do século XIX.

\section{Estado da arte}

De acordo com Hueck $\left(1965^{1}, 1968^{2}\right.$ apud ALLSOPP; SEAL; GAYLARDE, 2010), caracteriza-se como biodeterioração o processo que resulta na mudança indesejável das propriedades de um material causada pela atividade vital de organismos. O fenômeno da biodeterioração pode ocorrer em diversos tipos de materiais, de acordo com a interação de diferentes variáveis, tais como a natureza e a característica do substrato, o tipo de organismo envolvido e, sobretudo, as condições ambientais.

Caneva, Nugari e Salvadori (2000) sugerem que a biodeterioração dos materiais pode ocorrer através de mecanismos de distintos tipos: processos físicos ou mecânicos (desagregação ou fratura); e processos químicos (decomposição). Geralmente, estes ocorrem de forma simultânea, contudo, dependendo dos agentes responsáveis pela degeneração, do tipo de substrato e das condições ambientais, podem predominar os primeiros ou os segundos.

\footnotetext{
${ }^{1}$ HUECK, H. J. The Biodeterioration of Materials as Part of Hylobiology. Mater Org., v. 1, n. 1, p. 5-34, 1965.

${ }^{2}$ HUECK, H. J. The Biodeterioration of Materials: an appraisal. In: WALTERS, A. H.; ELPHICK, J. S. (Eds.). Biodeterioration of Materials. London: Elsevier, 1968. p. 6-12.
} 
Os fungos filamentosos são os agentes responsáveis pelo processo biodegenerativo reconhecido como bolor. Sob o ponto de vista morfológico, a presença de fungos é notada por meio da formação de manchas, que são devidas à liberação de pigmentos ou à presença do micélio, sendo este caracterizado como um conjunto de hifas, a unidade filamentosa do fungo.

Destaca-se ainda que, embora as manchas ocorram em um nível mais ou menos superficial dos materiais e possam causar danos principalmente de natureza estética, a penetração do micélio fúngico pode ser profunda em alguns tipos de superfície (até $10 \mathrm{~mm}$ ), causando perda de coesão e consequente desagregação do material (CANEVA; NUGARI; SALVADORI, 2000).

Mencionadas as questões relativas aos danos causados às superfícies dos materiais, faz-se necessário destacar os problemas relativos à saúde dos ocupantes de ambientes contaminados pelo bolor. Allsopp, Seal e Salvadori (2010) destacam que esporos de fungos, vivos ou mortos, especialmente quando presentes em grande quantidade, podem desencadear processos alérgicos, como as rinites ou a asma em usuários de ambientes contaminados.

Segundo Nascimento e Cincotto (2003), os compostos orgânicos utilizados como fonte de alimento pelos fungos filamentosos podem ser encontrados em vários materiais utilizados na construção civil. Alguns sistemas de revestimento podem servir como fonte direta de nutrientes para os fungos; outros servem apenas como substrato, suportando seu desenvolvimento. O bolor é resultante da produção de uma massa de esporos assexuados, conhecidos como conídeos, cuja formação dá-se em estruturas reprodutivas especializadas. Os conídeos são dispersos pelo ar, água, insetos, além de outros meios, e, ao fixaremse a determinado substrato, podem germinar, produzindo novas colônias. A umidade é um fator condicionante para o aparecimento, manutenção e aumento em extensão do bolor. A temperatura, o pH e a quantidade de oxigênio disponíveis também caracterizam-se como fatores decisivos no desenvolvimento dos fungos. A Figura 1 mostra equematicamente o ciclo de reprodução assexuada dos fungos filamentosos.

Um esporo, ao germinar, produz as hifas. As hifas dos fungos degradadores secretam enzimas digestivas que atacam os materiais para quebrar a matéria orgânica. Estas podem diferenciar-se em variadas estruturas, desempenhando diversas funções, entre elas a de estrutura de fixação no substrato. Um conjunto de hifas caracteriza o micélio, parte macroscópia do fungo que se manifesta na superfície dos materiais.

A Tabela 1 descreve sinteticamente os fatores decisivos para a germinação e crescimento dos fungos, com a indicação dos valores mínimos e máximos para cada item (SEDLBAUER, 2001).

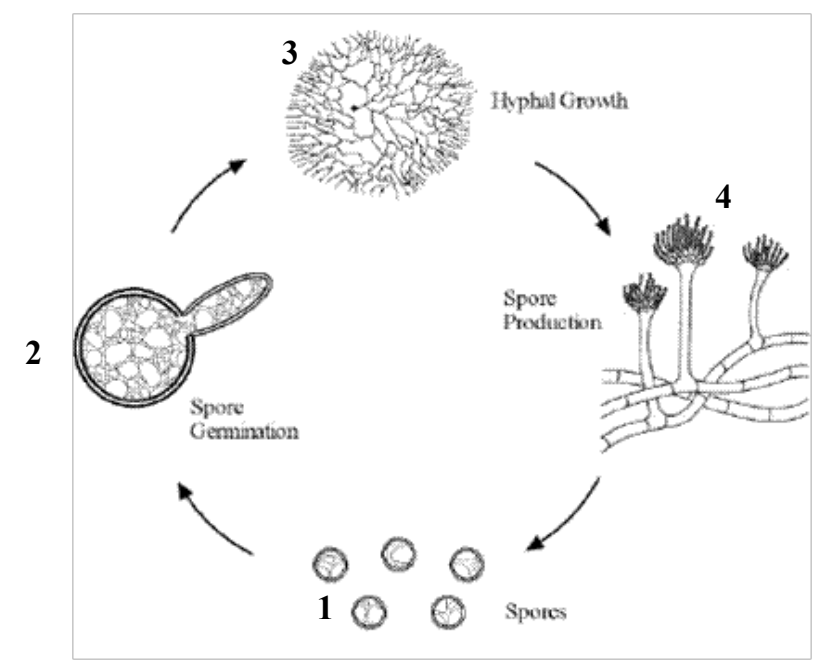

Figura 1 - Ciclo de vida dos fungos filamentosos

Fonte: Environmental Contrating Restoration (2012).

Nota: Legenda:

1: Esporos (conídeos) - estruturas microscópicas que podem estar dispersas no ar;

2: Germinação do esporo - crescimento de filamentos que formarão as hifas;

3: Micélio - conjunto de hifas que compõem uma massa visível macroscopicamente; e

4: Produção de novos esporos - formação dos conídeos (estruturas de reprodução). 
Tabela 1 - Fatores decisivos que influenciam o surgimento e a proliferação dos fungos

\begin{tabular}{|c|c|c|c|c|c|}
\hline \multirow{2}{*}{$\begin{array}{l}\text { Fator de } \\
\text { influência }\end{array}$} & \multirow{2}{*}{ Parâmetros } & \multirow{2}{*}{ Unid. } & \multicolumn{2}{|c|}{ Intervalo para o crescimento } & \multirow{2}{*}{ Comentários } \\
\hline & & & Mínimo & Máximo & \\
\hline Temperatura & $\begin{array}{l}\text { Temperatura } \\
\text { superficial da } \\
\text { parede }\end{array}$ & ${ }^{\circ} \mathrm{C}$ & -8 & 60 & \multirow{2}{*}{$\begin{array}{l}\text { Depende da espécie de } \\
\text { fungo e da fase de } \\
\text { desenvolvimento } \\
\text { (germinação de esporos } \\
\text { ou crescimento de } \\
\text { micélios) }\end{array}$} \\
\hline Umidade & $\begin{array}{l}\text { Umidade } \\
\text { relativa próximo } \\
\text { à superfície } \\
\end{array}$ & $\%$ & $70^{*}$ & 100 & \\
\hline Substrato & $\begin{array}{l}\text { Nutrientes e teor } \\
\text { de sal }\end{array}$ & - & - & - & $\begin{array}{l}\text { Os nutrientes podem } \\
\text { ser encontrados em } \\
\text { acúmulos de sujeira }\end{array}$ \\
\hline Ambiente & pH na superfície & - & 2 & 11 & $\begin{array}{l}\mathrm{O} \mathrm{pH} \text { também depende da } \\
\text { umidade relativa e da } \\
\text { temperatura do ar e é } \\
\text { influenciado pelos fungos. }\end{array}$ \\
\hline Tempo & $\begin{array}{l}\text { Quantidade de } \\
\text { horas por dia }\end{array}$ & $\mathrm{h} / \mathrm{d}$ & 1 & - & $\begin{array}{l}\text { Depende da } \\
\text { temperatura e umidade }\end{array}$ \\
\hline Atmosfera & $\begin{array}{l}\text { Quantidade de } \\
\text { oxigênio }\end{array}$ & $\%$ & 0,25 & - & Sempre presente \\
\hline
\end{tabular}

Fonte: modificado de Sedlbauer (2001).

Nota: *Há um tipo de fungo conhecido (Xeromyces) cujo crescimento pode ocorrer a partir de uma umidade relativa de $45 \%$.

Os dados apresentados na Tabela 1 mostram que o crescimento dos fungos filamentosos nas superfícies das edificações, em relação à temperatura superficial, pode ocorrer dentro de uma faixa bastante ampla, e que o aumento ou a diminuição dessa temperatura podem influenciar na germinação dos esporos desses fungos, de acordo com a espécie envolvida. Quanto à umidade, o crescimento é favorecido a partir de $70 \%$, o que não exclui a possibilidade de desenvolvimento de espécies mais resistentes a níveis mais baixos de umidade. O substrato ou a presença de nutrientes orgânicos presentes em partículas de sujeiras aderidas a ele são suficientes para seu metabolismo. Em relação ao pH, os fungos, através da secreção de substâncias químicas, auxiliares no processo de degradação dos nutrientes, produzem muitos ácidos, alterando em muitos casos o $\mathrm{pH}$ das superfícies. Outro aspecto importante a ser considerado é o tempo de exposição a esses fatores. A norma alemã DIN 4108-2 (DEUTSCHES..., 2003) passou a considerar esses parâmetros de forma a evitar o surgimento do bolor nas superfícies internas das edificações e, para tal, determinou como fatorlimite a umidade relativa próximo à superfície de $80 \%$ a um tempo máximo de exposição de $6 \mathrm{~h}$ por dia.

\section{Método}

O estudo foi realizado em um ambiente selecionado, em uma edificação do século XIX, na cidade de Pelotas, RS. Para tal foram realizadas cinco etapas de trabalho apontadas a seguir:

(a) levantamento de dados, levantamento fotográfico e análise visual das superfícies do ambiente selecionado da edificação histórica em estudo (Galeria de Arte Antônio Caringi do Casarão 2);

(b) revisão bibliográfica sobre os materiais e técnicas aplicados em edificações históricas do século XIX em Pelotas, para compreensão dos mecanismos que poderiam favorecer ou não a formação de bolor, bem como análise de documentação descritiva dos materiais e das técnicas construtivas adotados no prédio em estudo, disponível na Secretaria de Cultura do município;

(c) aplicação do método de coleta por $s w a b$ e análise em microscopia eletrônica para identificação dos gêneros dos fungos no local avaliado;

(d) determinação da temperatura e nível de umidade relativa do ar próximo à superfície da parede selecionada, considerando um regime de transferência de calor estacionário, através de cálculos com base na NBR 15220-2 (ABNT, 2005). A partir da determinação da transmitância térmica dessa parede foi possível calcular a temperatura superficial interna da parede analisada considerando um dia típico de inverno; e

(e) determinação da temperatura e nível de umidade relativa do ar das superfícies do ambiente, 
considerando um regime de transferência de calor transiente, com o auxílio de ferramenta computacional, o Software DesignBuilder versão 3.0.0.064.

\section{Levantamento de dados do prédio objeto de estudo da análise}

A residência do charqueador José Vieira Viana, também conhecida como Casarão 2 (Figuras 2 e $3)$, é tombada em âmbito federal pelo Iphan e apresenta uma área construída de $1.186,73 \mathrm{~m}^{2}$. Atualmente no prédio funcionam o Centro Cultural Adail Bento Costa e a Secretaria de Cultura do município. O prédio foi construído em 1830 e reformado em 1880. Mais recentemente, em 2005, passou por processo de restauração.
O compartimento selecionado, Galeria de Arte Antônio Caringi, localiza-se no térreo e possui duas de suas faces voltadas para as fachadas oeste e sul, em destaque na planta baixa da edificação, mostrada na Figura 4. Esse ambiente foi escolhido por apresentar características pertinentes à investigação proposta, tais como:

(a) faz parte de uma edificação histórica;

(b) apresenta manifestação de bolor;

(c) desempenha uma função que envolve a movimentação constante de pessoas, como uma galeria de arte; e

(d) possui os elementos necessários ao desenvolvimento da pesquisa, como amostras de material, documentação disponível, além do acesso fácil ao ambiente.

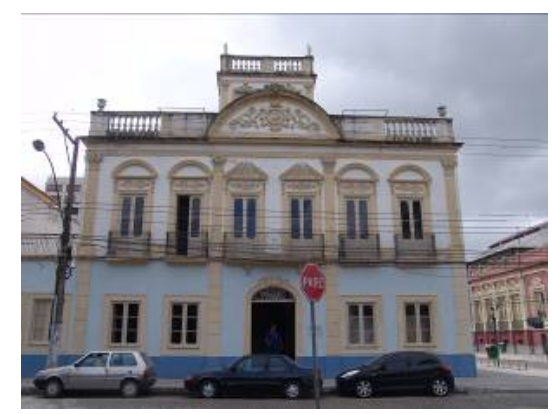

Figura 2 - Casarão 2 - Fachada oeste

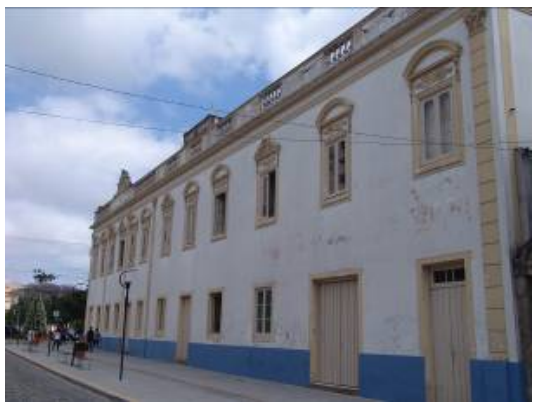

Figura 3 - Casarão 2 - Fachada sul

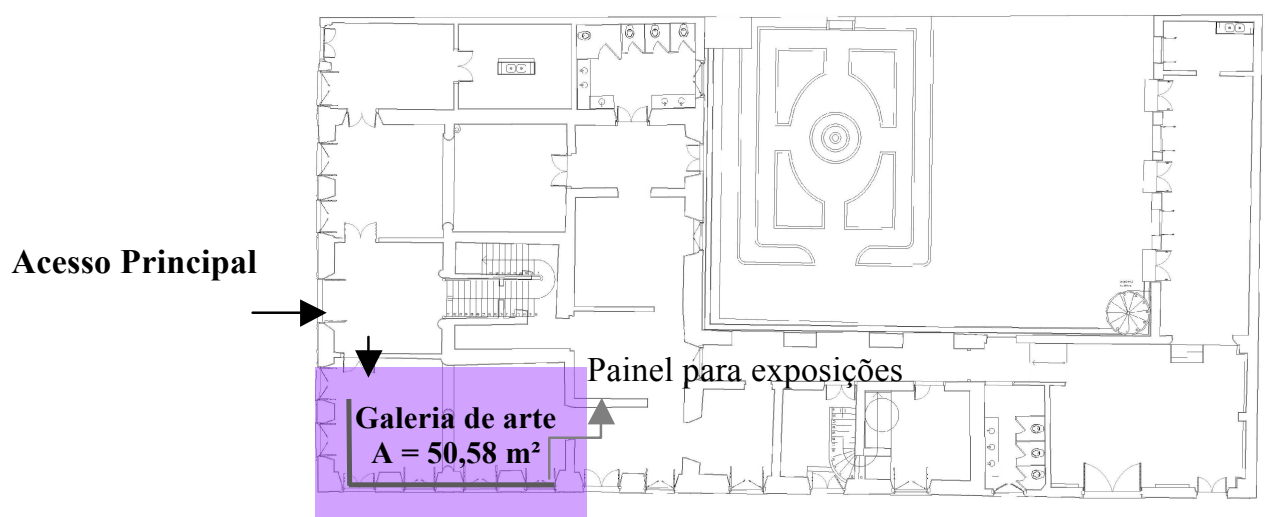

Figura 4 - Planta baixa do pavimento térreo do Casarão 2

Fonte:Secretaria Municipal de Cultura de Pelotas (2002). 
Destaca-se que em toda a extensão das paredes exteriores, onde estão as esquadrias, foram posicionados painéis de madeira, fixos, onde é colocado o material de exposição da galeria. Esses painéis não alcançam o teto da sala, conforme demonstrado na Figura 5.

Para esse compartimento foi definido um módulo da parede sul, com espessura de $0,78 \mathrm{~m}$, rebocada em ambos os lados.

As Figuras 5 e 6 mostram o local onde foi detectada a presença do bolor. Em destaque na Figura 7 a presença de painéis que estão distribuídos em toda a extensão das paredes e são utilizados para a colocação do material em exposição na galeria. A Figura 6 mostra uma aproximação do ponto onde foi detectada a presença do bolor, destacando a extensão do dano. A Figura 7 mostra o mapeamento das fotos obtidas no levantamento.

\section{Abordagem geral a respeito dos materiais e técnicas em edificações históricas de Pelotas (século XIX)}

Grande parte das edificações construídas no século XIX em Pelotas foi projetada e executada por construtores italianos, que nesse município atuaram principalmente no final do século XIX e início do XX. Com base em manuais de construção da época, descritos por Peres (2008), a técnica construtiva aplicada na maioria das edificações era basicamente como a descrita na Tabela 2 .

Figura 5 - Ambiente analisado
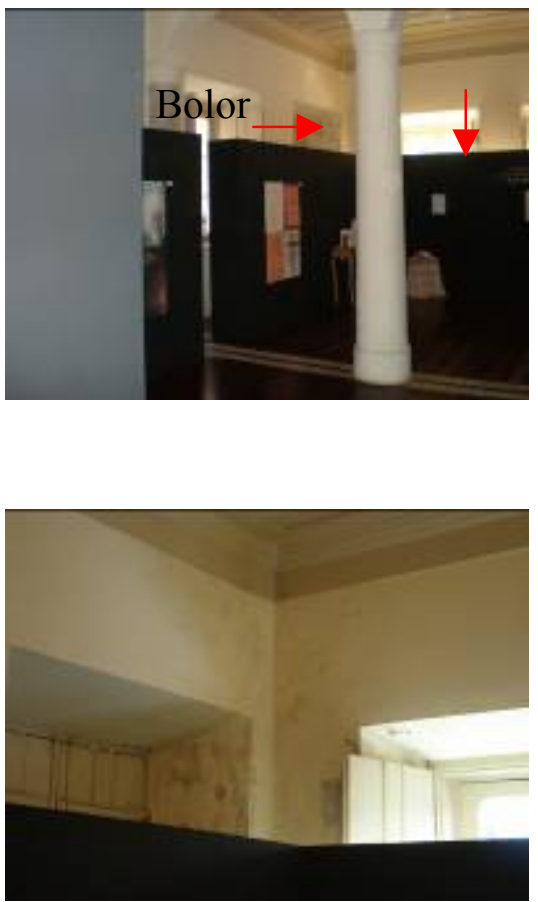

Figura 6 - Aproximação da superfície analisada

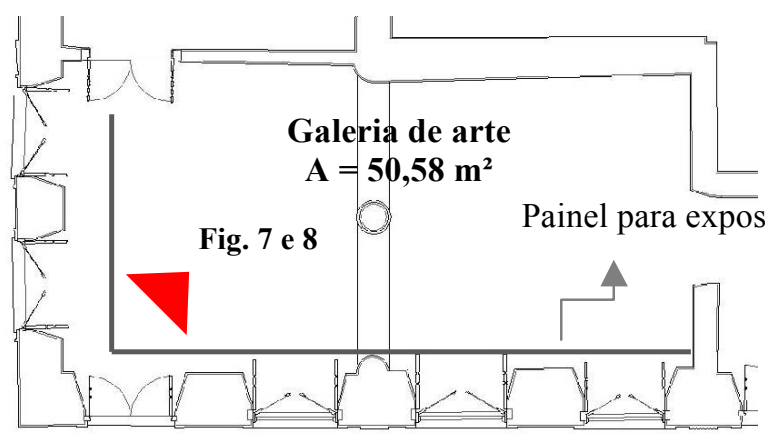

Figura 7 - Planta baixa da Galeria de Arte - Mapa das Figuras 7 e 8 
Tabela 2 - Técnicas construtivas de edificações do século XIX em Pelotas

\begin{tabular}{l|l}
\hline \multicolumn{2}{c}{ SÍNTESES DAS TÉCNICAS CONSTRUTIVAS NAS EDIFICAÇÕES HISTÓRICAS } \\
\hline \multicolumn{1}{c}{ Componentes } & \multicolumn{1}{c}{ Características } \\
\hline FUNDAÇÕES & \multicolumn{1}{c}{ Diretas, em pedra granítica, rejunte em argamassa. } \\
\hline PAREDES & $\begin{array}{c}\text { Portantes, em alvenaria de tijolo cerâmico, argamassa de cal e areia. } \\
\text { Externas }(60-80 \mathrm{~cm})\end{array}$ \\
& \multicolumn{1}{|c}{ Internas: $(50-60 \mathrm{~cm})$} \\
\hline Internas (estuque: em torno de $15 \mathrm{~cm})$
\end{tabular}

Fonte: adaptado de Peres (2008).

De acordo com as descrições dessa tabela, essas edificações eram projetadas com paredes portantes de grande espessura, reduzindo a transmitância térmica e aumentando consideravelmente a capacidade térmica. Esse tipo de alvenaria, em conjunto com outros fatores, como nível de ventilação e incidência solar adequados, comportava-se como o principal mecanismo responsável pelo conforto térmico delas. Os grandes vãos das esquadrias, seu posicionamento e o elevado pé-direito permitiam boas condições de ventilação e qualidade do ar.

Para o ambiente em estudo nesta edificação é possível relacionar a colocação dos painéis para a fixação do material de exposição da galeria ao agravamento do problema do bolor, pelo fato de este criar uma barreira que impede a circulação livre do ar. Outra questão a ser considerada é em relação ao manuseio das esquadrias, que, por estarem em local de difícil acesso, atrás dos painéis, não são frequentemente abertas. Dessa forma, é possível que nas superfícies da parede logo atrás desses painéis esteja ocorrendo maior retenção de umidade e consequente alteração na temperatura superficial da parede, o que pode favorecer o agravamento do problema.

\section{Coleta e identificação dos fungos}

A partir dos danos identificados na análise in loco foram determinados quatro pontos para a coleta das amostras. Todos os pontos foram selecionados na superfície da parede que possui a face externa voltada ao sul, onde se detectou alteração na coloração de forma mais efetiva. O procedimento de coleta corresponde à utilização de $s w a b^{3}$ estéril umedecido em água destilada. O swab é passado sobre a região onde foi identificado sinal de ataque microbiológico. O material coletado foi inserido

\footnotetext{
${ }^{3}$ Haste flexível com algodão.
}

em um tubo de ensaio e, em seguida, vedado para transporte ao laboratório.

Foram tomadas as devidas precauções para que não ocorresse contaminação durante a etapa de coleta e transporte, sendo fundamentais as condições de esterilização, assepsia e o não contato manual com o material coletado.

O material coletado foi conduzido ao laboratório de microbiologia e semeado em placas de Petri ${ }^{4}$ com meio de cultura favorável ao desenvolvimento de fungos. As placas contaminadas foram mantidas em uma estufa por aproximados 6 dias, com temperatura em torno de $25{ }^{\circ} \mathrm{C}\left(+/-2{ }^{\circ} \mathrm{C}\right)$ com fotoperíodo de $12 \mathrm{~h}$. Após verificação do crescimento das colônias dos gêneros fúngicos, a partir dos aspectos macroscópicos, foram montadas lâminas para análise microscópica e identificação dos gêneros dos fungos.

\section{Determinação da temperatura da superfície interna da parede selecionada através do método de regime de transferência de calor estacionário}

Identificados os gêneros dos fungos causadores do bolor, iniciou-se o procedimento de determinação da temperatura superficial da parede selecionada. Para tal, fez-se necessária a aplicação de uma série de procedimentos, demonstrados no Fluxograma (Figura 8), para a obtenção dos dados e possível correlação dos fatores temperatura superficial e umidade próxima à superfície com os fatoreslimites favoráveis ao surgimento e desenvolvimento do bolor.

\footnotetext{
${ }^{4}$ Recipientes de material plástico ou de vidro, com tampa para armazenamento do meio de cultura e desenvolvimento dos micro-organismos.
} 


\section{LABORATÓRIO DE MATERIAIS DE CONSTRUÇÃO}

- Determinação da umidade natural e umidade saturada de amostras de tijolo e argamassa obtidas do prédio

- Determinação da massa específica das amostras - Método do Picnômetro

- Determinação de todos os índices físicos das amostras, tais como grau de saturação, compacidade, coeficiente de aeração, teor de umidade e massa unitária (densidade)

Com os valores das densidades dos materiais e com o auxílio da NBR 15220, parte 2, verificou-se a condutividade térmica e o calor específico dos materiais.

Com base na definição da temperatura mínima para inverno, $12{ }^{\circ} \mathrm{C}$ (Projeto de norma 02:136.01.001 - Desempenho de edifícios habitacionais de até 5 pavimentos - Parte 1: Requisitos gerais, 2004) e considerando um regime constante de troca de calor, foram calculados o fluxo de calor e as temperaturas superficiais nas diferentes camadas da parede analisada pela fórmula demonstrada no Quadro 1.

Figura 8 - Etapas realizadas para determinação dos valores de densidades a serem aplicados no cálculo para verificação do fluxo de calor e temperaturas

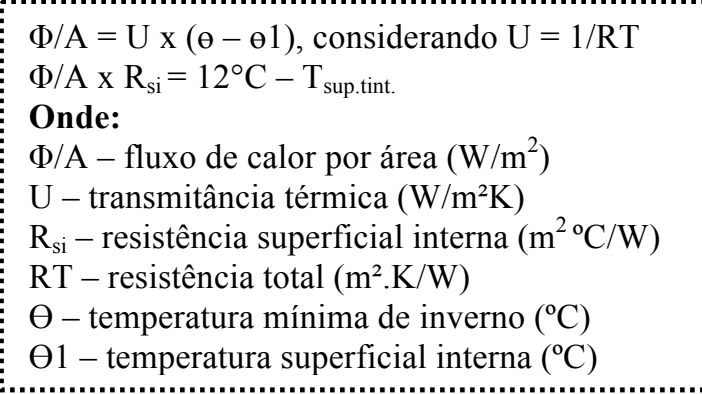

Quadro 1 - Determinação do fluxo de calor e das temperaturas superficiais

\section{Determinação da densidade de massa aparente, condutividade térmica e calor específico dos materiais que compõem a superfície analisada}

As amostras de tijolo e argamassa de revestimento foram obtidas em um ambiente próximo ao local do estudo, na mesma edificação, em um ponto onde foi feito um furo para passagem de fiação elétrica. Não foi possível adquirir o material no ambiente que está sendo analisado por não haver nenhum ponto possível de retirada de material sem causar alterações visíveis na superfície, destacando-se que se trata de uma edificação patrimonial. Também não se optou por retirar o material do ponto onde está acelerado o processo degenerativo, devido ao estado avançado de desagregação dos materiais.

(a) determinação da densidade de massa aparente ( $\rho)$ do tijolo:

$\rho=1.800 \mathrm{~kg} / \mathrm{m}^{3}$ (densidade de massa aparente); $\lambda=1,05 \mathrm{~W} /(\mathrm{m} . \mathrm{K})$ (condutividade térmica); e $\mathrm{c}=0,92 \mathrm{~kJ} /(\mathrm{kg} . \mathrm{K})$ (calor específico do material).

(b) determinação da densidade de massa aparente ( $\rho)$ da argamassa:

$\rho=1.990 \mathrm{~kg} / \mathrm{m}^{3}$ (densidade de massa aparente);

$\lambda=1,15 \mathrm{~W} /(\mathrm{m} . \mathrm{K})$ (condutividade térmica); e

$\mathrm{c}=1,00 \mathrm{~kJ} /(\mathrm{kg} . \mathrm{K})$ (calor específico do material).

Com base nesses valores, através da aplicação dos cálculos apresentados em norma (NBR 15220-2 (ABNT, 2008)), foi possível determinar a transmitância térmica do módulo da parede selecionada no prédio em estudo.

\section{Determinação da transmitância}

A Tabela 3 mostra a sequência de cálculos aplicados para a obtenção do valor da transmitância térmica no módulo de parede selecionado, com base na NBR 15220-2 (ABNT, 
2008): métodos de cálculo da transmitância térmica, da capacidade térmica, do atraso térmico e do fator de calor solar dos elementos e componentes de edificações.

O módulo é composto de uma fiada de 2 tijolos à tição e de 1 tijolo lateral (meia parede), como mostra a Figura 9. Essa disposição pôde ser determinada com base em imagens obtidas de trechos de parede com a alvenaria, exposta durante o processo de intervenção de restauro na edificação, sendo reforçada com base em Breymann (2003).

\section{Determinação das temperaturas internas}

Conhecido o valor da transmitância térmica da parede, foi possível calcular a temperatura superficial interna para as diferentes camadas que compõem a parede do ambiente estudado. Adotouse a definição da temperatura mínima para inverno, $12{ }^{\circ} \mathrm{C}$, em consonância com o projeto de norma 02:136.01.001 e a temperatura externa de $5{ }^{\circ} \mathrm{C}$ (COSTA, 1982). Aplicaram-se diferentes resistências superficiais internas, com base na norma brasileira NBR 15220-3 (ABNT, 2005) e na norma alemã DIN 4108-03 (2001), para ambientes aquecidos e não aquecidos.

Considerando a $\mathrm{t}_{\mathrm{e}}=5^{\circ} \mathrm{C}$ e a $\mathrm{t}_{\mathrm{i}}=12{ }^{\circ} \mathrm{C}, \Delta \mathrm{T}=7{ }^{\circ} \mathrm{C}$

$\Phi / \mathrm{A}=\mathrm{U} \times \Delta \mathrm{T}$

$\mathrm{U}=1,12 \mathrm{~W} / \mathrm{m}^{2} \mathrm{~K}$; e

$\Phi / \mathrm{A}=1,12 \times 7=7,84 \mathrm{~W} / \mathrm{m}^{2}$.

$\Phi / \mathrm{A}=\mathrm{U} \times(\Theta-\Theta 1)$, considerando que $\mathrm{U}=1 / \mathrm{R}$, obtém-se:

$\Phi / \mathrm{A} \times \mathrm{R}_{\mathrm{Si}}=12^{\circ} \mathrm{C}-\mathrm{T}_{\text {sup.int }}$.

A Figura 10 mostra as diferentes camadas que compõem a superfície em estudo, destacando os diferentes pontos de onde se calculou a temperatura superficial.
1) Calculando as temperaturas para as diferentes camadas aplicando-se a resistência superficial indicada pela NBR 15220-2 (ABNT, 2008), $\mathrm{R}_{\mathrm{si}}=$ $0,13 \mathrm{~m}^{2} \mathrm{C} / \mathrm{W}$

1.1) Calculando a temperatura junto à superfície do painel (T1),

$$
\begin{aligned}
& \Phi / \mathrm{A} \times \mathrm{R}_{\mathrm{Si}}=12{ }^{\circ} \mathrm{C}-\mathrm{T}_{\text {sup.int }} \cdot 1 \\
& \Phi / \mathrm{A}=7,84 \mathrm{~W} / \mathrm{m}^{2} \\
& \mathrm{R}_{\mathrm{si}}=0,13, \operatorname{logo}: 7,84 \times 0,13=12-\mathrm{T}_{\text {sup.int }}=10,98 \\
& { }^{\circ} \mathrm{C} \\
& \mathrm{T} 1=10,98^{\circ} \mathrm{C}
\end{aligned}
$$

1.2) Calculando a temperatura na superfície interna do painel de madeira (T2)

$$
\Phi / \mathrm{A} \times \mathrm{R}_{\text {madeira }}=10,98^{\circ} \mathrm{C}-\mathrm{T}_{\text {sup.int }} .2
$$

7,84 $\mathrm{x}$ espessura da madeira/condutividade térmica da madeira $=10,98-\mathrm{T}_{\text {sup.int }} \cdot 2$

7,84 x 0,01/0,058 (aglomerado leve, NBR 15220-2 $(\mathrm{ABNT}, 2008))=10,98-\mathrm{T}_{\text {sup.int. }} \cdot 2=9,63^{\circ} \mathrm{C}$

$\mathrm{T} 2=9,63{ }^{\circ} \mathrm{C}$

1.3) Calculando a temperatura na camada de ar (T3)

$7,84 \times$ (camada de ar maior do que $5 \mathrm{~cm}$, NBR $15220-2\left(\right.$ ABNT, 2008), $\left.\mathrm{R}_{\mathrm{si}}=0,17\right)=9,63{ }^{\circ} \mathrm{C}-$ $\mathrm{T}_{\text {sup.int. }} 3$

$7,84 \times 0,17=9,63-\mathrm{T}_{\text {camada }} \cdot 3=8,30^{\circ} \mathrm{C}$

$\mathrm{T} 3=8,30^{\circ} \mathrm{C}$

1.4) Calculando a temperatura na superfície da parede de alvenaria (T4)

$7,84 \times \mathrm{R}_{\text {superficial da parede }}=8,30^{\circ} \mathrm{C}-\mathrm{T}_{\text {sup.int }} \cdot 4=7,84 \mathrm{x}$ $0,13=8,30^{\circ} \mathrm{C}-\mathrm{T}_{\text {sup.int }} \cdot 4=7,28^{\circ} \mathrm{C}$

$\mathrm{T} 4=7,28^{\circ} \mathrm{C}$
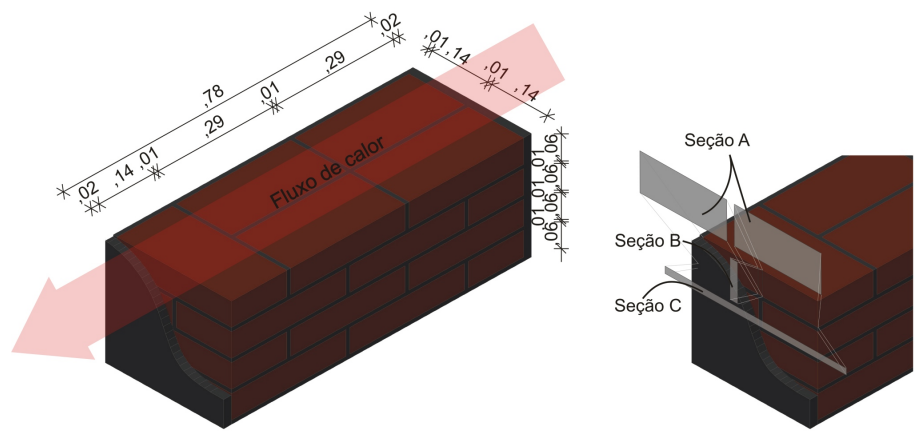

Figura 9 - Módulo de parede oeste para aplicação do estudo e seções identificadas para o cálculo da transmitância 
Tabela 3 - Sequência de cálculos aplicados para a obtenção do valor da transmitância térmica no módulo de parede selecionado

\section{Parede de espessura $78 \mathrm{~cm}-14 \times 29 \times 6$}

Seção A - reboco+tijolo+argamassa+tijolo+argamassa+tijolo+reboco

$$
\text { Área }
$$

$$
A=2 \times(0,14 \times 0,6)
$$

\begin{tabular}{l|c|c}
\hline \multicolumn{1}{c|}{ Área $\left(\mathbf{m}^{\mathbf{2}}\right)$} & 0,0168 & Resistências $-\mathrm{e} / \boldsymbol{\lambda}\left(\mathrm{m}^{2} . \mathrm{K} / \mathrm{W}\right)$ \\
\hline Espessuras & Espessura $(\mathrm{m})$ & 0,0174 \\
\hline Reboco & 0,02 & 0,2762 \\
\hline Tijolo & 0,29 & 0,0087 \\
\hline Argamassa & 0,01 & 0,2762 \\
\hline Tijolo & 0,29 & 0,0087 \\
\hline Argamassa & 0,01 & 0,1333 \\
\hline Tijolo & 0,14 & 0,0174 \\
\hline Reboco & 0,02 & $\mathbf{0 , 7 3 7 9} \mathrm{m}^{2} \cdot \mathrm{K} / \mathrm{W}$ \\
\hline \multicolumn{2}{|c}{ reboco + tijolo + argamassa + reboco } \\
\hline Resistência total & $0,78 \mathrm{~m}$ & $\mathbf{A r}$
\end{tabular}

\begin{tabular}{lrr}
$\mathrm{R}_{\text {reboco }}+\mathrm{R}_{\text {tijolo }}+\mathrm{R}_{\text {argamassa }}+\mathrm{R}_{\text {tijolo }}+\mathrm{R}_{\text {argamassa }}+\mathrm{R}_{\text {tijolo }}+\mathrm{R}_{\text {reboco }}$ & $\mathbf{0 , 7 3 7 9} \mathrm{m}^{2} . \mathrm{K}$ \\
\hline Seção $\mathbf{B}$ & reboco + tijolo + argamassa + reboco \\
\hline
\end{tabular}

$$
A=0,01 \times 0,06
$$

\begin{tabular}{|c|c|c|}
\hline$\overline{\text { Seção C }}$ & \multicolumn{2}{|c|}{ reboco+argamassa+reboco } \\
\hline \multicolumn{3}{|c|}{$\begin{array}{c}\text { Área } \\
A=(0,01 \times 0,07)+(0,31 \times 0,01)\end{array}$} \\
\hline Área & 0,0038 & \\
\hline Espessuras & Espessura (m) & Resistência $=\mathrm{e} / \lambda\left(\mathrm{m}^{2} . \mathrm{K} / \mathrm{W}\right)$ \\
\hline Reboco & 0,02 & 0,0174 \\
\hline Argamassa & 0,74 & 0,6435 \\
\hline \multirow[t]{2}{*}{ Reboco } & 0,02 & 0,0174 \\
\hline & $0,78 \mathrm{~m}$ & \\
\hline \multicolumn{3}{|c|}{ Resistência total } \\
\hline \multicolumn{2}{|c|}{$\mathrm{R}_{\text {reboco }}+\mathrm{R}_{\text {argamassa }}+\mathrm{R}_{\text {reboco }}$} & $\mathbf{0 , 6 7 8 3} \mathrm{m}^{2} . \mathrm{K} / \mathrm{W}$ \\
\hline \multicolumn{3}{|c|}{ Resistência total de superfície a superfície } \\
\hline \multicolumn{3}{|c|}{$\mathrm{Rt}=(\mathrm{A} \times \mathrm{R})_{\mathrm{A}}+(\mathrm{A} \times \mathrm{R})_{\mathrm{B}}+(\mathrm{A} \times \mathrm{R}) \mathrm{C} / \mathrm{A}_{\mathrm{A}}+\mathrm{A}_{\mathrm{B}+\mathrm{AC}}$} \\
\hline $\mathbf{R t}$ & \multicolumn{2}{|l|}{$0,7258 \mathrm{~m}^{2} . \mathrm{K} / \mathrm{W}$} \\
\hline RT & \multicolumn{2}{|l|}{$0,8958 \mathrm{~m}^{2} . \mathrm{K} / \mathrm{W}$} \\
\hline Transmitância & $\mathrm{U}\left(\mathrm{W} / \mathrm{m}^{2} \mathrm{~K}\right)$ & \\
\hline $\mathrm{U}=\mathbf{1} / \mathrm{RT}$ & 1,12 & \\
\hline
\end{tabular}

\begin{tabular}{l|c|c}
\hline \multicolumn{1}{c|}{ Área } & 0,0006 & \\
\hline Espessuras & Espessura $(\mathrm{m})$ & Resistência $=\mathrm{e} / \lambda\left(\mathrm{m}^{2} . \mathrm{K} / \mathrm{W}\right)$ \\
\hline Reboco & 0,02 & 0,0174 \\
\hline Tijolo & 0,14 & 0,1333 \\
\hline Argamassa & 0,60 & 0,5217 \\
\hline Reboco & 0,02 & 0,0174 \\
\hline \multicolumn{2}{c|}{ Resistência total $^{-1}$} & $\mathbf{0 , 6 8 9 9} \mathrm{m}^{2} . \mathrm{K} / \mathrm{W}$ \\
\hline \multicolumn{2}{c|}{$\mathrm{R}_{\text {reboco }}+\mathrm{R}_{\text {tijolo }}+\mathrm{R}_{\text {argamassa }}+\mathrm{R}_{\text {reboco }}$} &
\end{tabular}

Parede de alvenaria rebocada em ambos os lados

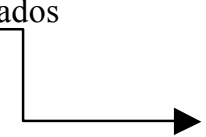

Figura 10 - Temperaturas superficiais das diferentes camadas

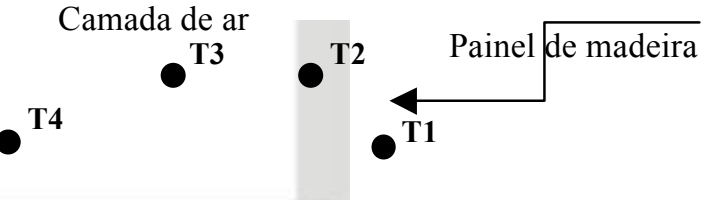


2) Calculando as temperaturas para as diferentes camadas aplicando-se a resistência superficial indicada pela DIN 4108-3 (DEUTSCHES..., 2001), para ambientes aquecidos $\mathrm{R}_{\mathrm{si}}=0,25 \mathrm{~m}^{2}$ ${ }^{\circ} \mathrm{C} / \mathrm{W}$

2.1) Calculando a temperatura junto à superfície do painel (T1),

$7,84 \times 0,25=12-\mathrm{T}_{\text {sup.int. }} \cdot 1=10,04^{\circ} \mathrm{C}$

$\mathrm{T} 1=10,04^{\circ} \mathrm{C}$

2.2) Calculando a temperatura na superfície interna do painel de madeira (T2)

$7,84 \times 0,01 / 0,058=10,04-\mathrm{T}_{\text {sup.int }} \cdot 2=8,69^{\circ} \mathrm{C}$

$\mathrm{T} 2=8,69^{\circ} \mathrm{C}$

2.3) Calculando a temperatura na camada de ar (T3)

$7,84 \times 0,17=8,69-\mathrm{T}_{\text {sup.int }} \cdot 3=7,35^{\circ} \mathrm{C}$

$\mathrm{T} 3=7,35^{\circ} \mathrm{C}$

2.4) Calculando a temperatura na camada de ar (T4)

$7,84 \times 0,25=7,35-\mathrm{T}_{\text {sup.int. }} 4=5,39^{\circ} \mathrm{C}$

$\mathrm{T} 4=5,39{ }^{\circ} \mathrm{C}$

3) Calculando as temperaturas para as diferentes camadas aplicando-se a resistência superficial indicada pela DIN 4108-3 (DEUTSCHES..., 2001), para ambientes não aquecidos $R_{\mathrm{si}}=0,17 \mathrm{~m}^{2}$ ${ }^{\circ} \mathrm{C} / \mathrm{W}$

3.1) Calculando a temperatura junto à superfície do painel (T1),

$7,84 \times 0,17=12-\mathrm{T}_{\text {sup.int. } 1}=10,66{ }^{\circ} \mathrm{C}$

$\mathrm{T} 1=10,66^{\circ} \mathrm{C}$

3.2) Calculando a temperatura na superfície interna do painel de madeira (T2)

$7,84 \times 0,01 / 0,058=10,66-\mathrm{T}_{\text {sup.int. } 2}=9,30{ }^{\circ} \mathrm{C}$

$\mathrm{T} 2=9,30{ }^{\circ} \mathrm{C}$

3.3) Calculando a temperatura na camada de ar (T3)

$7,84 \times 0,17=9,30-\mathrm{T}_{\text {sup.int. } 3}=7,97^{\circ} \mathrm{C}$

$\mathrm{T} 3=7,97^{\circ} \mathrm{C}$

3.4) Calculando a temperatura na camada de ar (T4)

$7,84 \times 0,17=7,97-\mathrm{T}_{\text {sup.int. } 4}=6,63{ }^{\circ} \mathrm{C}$

$\mathrm{T} 4=6,63^{\circ} \mathrm{C}$

\section{Definição da umidade relativa próximo à superfície da parede considerando o regime de transferência de calor estacionário}

Segundo dados da Embrapa (EMPRESA..., 2010) sobre as Normais Climatológicas para a cidade de Pelotas, a umidade relativa média no inverno é de $84 \%$. Com base na carta psicrométrica, para a temperatura de externa de $5{ }^{\circ} \mathrm{C}$, a umidade absoluta é de 4,2 g de vapor d'água/ $\mathrm{kg}$ ar seco.

Considerou-se a temperatura mínima para inverno, $12^{\circ} \mathrm{C}$, em consonância com a NBR 15575 (ABNT, 2008) e a temperatura externa de $5{ }^{\circ} \mathrm{C}$ (COSTA, 1982). Em relação ao número de renovações do ar do espaço interior, adotou-se em torno de 1 renovação por hora, acordando com Toledo (1999) e Lamberts (1997), e 0,5 renovação por hora, acordando com a DIN 4108-3 (2003 ${ }^{5}$ apud CUNHA; FRITSCH, 2009).

Considerando 1 renovação do ar por hora, desconsiderando fontes internas de geração de vapor ou superfícies abaixo do ponto de orvalho, que gerariam condensação, bem como qualquer elemento de absorção ou adsorção de umidade, o conteúdo de umidade interno foi considerado igual ao externo, portanto $\mathrm{UA}=4,2 \mathrm{~g} / \mathrm{kg}$.

Para uma renovação de 0,5 por hora, calculou-se a média da umidade absoluta exterior e a umidade absoluta do ambiente. $\mathrm{O}$ ambiente analisado possui volume $(\mathrm{V})=199,80 \mathrm{~m}^{3}$. Considerou-se que cerca de 17 pessoas circulam por hora nesse ambiente. Com base na DIN 4108-3 (DEUTSCHES..., 2003), cada pessoa libera em torno de $60 \mathrm{~g}$ de vapor d'água por hora, portanto, $\mathrm{UA}=4,2 \mathrm{~g} / \mathrm{kg}$.

Com os valores das temperaturas superficiais internas, considerando a umidade absoluta interna tanto para 0,5 como para 1 troca por hora $(\operatorname{Ren} / \mathrm{h})$, com base na carta psicrométrica, foi possível obter os valores das umidades relativas próximas à superfície da parede.

\section{Determinação da temperatura e nível de umidade relativa do ar das superfícies do ambiente considerando- se um regime de transferência de calor transiente}

O programa de simulação escolhido para a análise nesse estudo é o DesignBuilder. O software
5 DEUTSCHES INSTITUT FÜR NORMUNG. DIN 4108-3: Wärmeschutz und Energie-Einsparung in Gebäuden. Teil 3: Klimabedingter Feuchteschutz, Anforderungen, Berechnungsverfahren und Hinweise für Planung und Ausführung. Berlin, 2001. 
fornece uma extensa gama de dados de desempenho ambiental, que podem ser utilizados para várias análises de desempenho térmico, consumo de energia, estratégias de sombreamento solar, entre outras. Os resultados de saída podem ser obtidos por períodos mensais, diários, horários e sub-horários. A partir dessas informações, é possível fazer uma avaliação da edificação como um todo, ou por ambientes específicos.

Pelotas ainda não possui um arquivo climático próprio. Por esta razão, o utilizado para a simulação foi o arquivo referente à cidade de Santa Maria (BRA_Santa.Maria.839360_SWERA.epw), cidade que está situada na mesma zona bioclimática de Pelotas, ZB 2 (NBR 15220-3 (ABNT, 2005)).

Por se tratar do estudo de uma edificação histórica, com características peculiares, várias simplificações das características construtivas tiveram de ser feitas no que diz respeito apenas à modelagem tridimensional do edifício, como, por exemplo, a padronização das espessuras das paredes. Como no cálculo dos fluxos de calor, a espessura das paredes é dependente da caracterização do número e da espessura das camadas, esta simplificação influi apenas no tamanho das zonas térmicas. A edificação possui uma grande variação na espessura das paredes internas e externas. A solução escolhida foi a de modelar as paredes externas com $20 \mathrm{~cm}$ de espessura, e as internas com $35 \mathrm{~cm}$, e indicar as camadas com suas espessuras reais e características de cada material na configuração de construção do programa. As camadas foram deduzidas a partir de Breymann (2003), para melhor se adequarem às construções da época (Figura 11). Foram consideradas as camadas com maior número de materiais para configuração das paredes.

A modelagem do Casarão 2 no programa de simulação computacional Software DesignBuilder (versão 3.0.0.064) considerou todas as peculiaridades da edificação, como, por exemplo, as características originais dos materiais (obtidas por ensaios, descritos em Determinação da temperatura da superfície interna da parede selecionada através do método de regime de transferência de calor estacionário), espessuras de paredes e tipos de janelas. Com o levantamento feito no local foi possível determinar a densidade de carga interna a partir do número de pessoas em cada ambiente e o tipo de iluminação. A edificação que é totalmente ventilada naturalmente adotou a temperatura de $25^{\circ} \mathrm{C}$ como set point de ventilação (MARTINS et al., 2009). A abertura das janelas é feita a partir do set point e pelos horários de ocupação do casarão, que também foram obtidos pelo levantamento feito no local. As janelas possuem postigos de madeira, que permitem a ventilação e o sombreamento parcial do ambiente, de acordo com a época do ano e a incidência solar direta em cada fachada.

\section{Análise de resultados}

\section{Gêneros dos fungos identificados no local analisado}

Com o objetivo de obter uma análise qualitativa, com a identificação dos principais gêneros de fungos envolvidos no processo degenerativo, foram selecionados quatro pontos de coleta para a obtenção das amostras.

Das amostras enviadas ao laboratório de microbiologia foram identificados cinco diferentes gêneros de fungos filamentosos, Penicillium, Paecilomyces, Cladosporium, Fusarium e Trichoderma.

Sedlbauer (2001) apresenta uma relação das principais espécies de fungos filamentosos já identificados, em que destaca as temperaturas mínimas, ótimas e máximas e as taxas de umidade relativas do ar ideais para a germinação dos esporos e crescimento dos micélios. A Tabela 4 destaca esses parâmetros para espécies dos diferentes gêneros de fungos identificados neste trabalho.

Conforme a Tabela 4, é possível verificar que os fungos do gênero Penicillium apresentam germinação dos esporos a uma temperatura do ar a partir dos $5^{\circ} \mathrm{C}$, destacando a espécie Penicillium expansum, que se desenvolve a temperaturas do ar inferiores a $0{ }^{\circ} \mathrm{C}$. Em relação à umidade relativa do ar, uma taxa mínima de $78 \%$ faz-se necessária para a germinação do esporo, contudo o crescimento do micélio mantém-se em uma taxa mínima de $75 \%$.
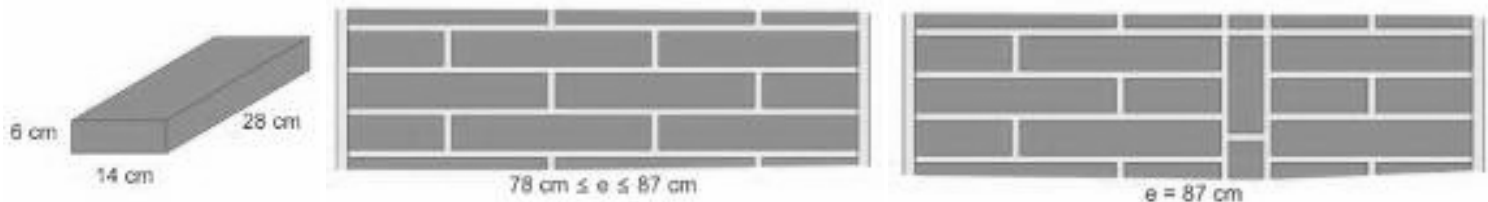

Figura 11 - Tijolo de referência e composições adotadas das paredes mais espessas 
Fonte: adaptado de Breymann (2003).

Tabela 4 - Especificação de valores para os parâmetros de umidade relativa e temperatura de diferentes espécies de fungos

\begin{tabular}{|c|c|c|c|c|c|c|c|c|c|c|}
\hline \multirow{3}{*}{ Espécie do fungo } & \multicolumn{6}{|c|}{ Temperatura $\left({ }^{\circ} \mathrm{C}\right)$} & \multicolumn{4}{|c|}{ Umidade Relativa (\%) } \\
\hline & \multicolumn{3}{|c|}{ Germinação do esporo } & \multicolumn{3}{|c|}{ Crescimento do micélio } & \multicolumn{2}{|c|}{ Germ. do esporo } & \multicolumn{2}{|c|}{ Cresc. Micélio } \\
\hline & mín. & ótimo & máx. & mín. & ótimo & máx. & mín. & ótimo & mín. & ótimo \\
\hline Penicillium brevicompactum & 5 & 25 & 32 & -2 & 25 & 30 & 78 & & 75 & 96 \\
\hline Penicillium citrinum & & & & & & & 84 & & 80 & \\
\hline Penicillium crysogenum & & & & -4 & 28 & 38 & 78 & & 79 & 98 \\
\hline Penicillium cyclopium & 5 & 25 & 33 & 2 & 25 & 37 & 80 & 97 & 80 & 98 \\
\hline Penicillium expansum & $<0$ & & & -3 & 26 & 35 & 82 & & 82 & 95 \\
\hline Paecilomyces lilachinus & & & & & 35 & 60 & 84 & & 84 & \\
\hline Cladosporium cladosporioides & & & & -5 & 28 & 32 & 85 & & 84 & 96 \\
\hline Cladosporium sphaerosperum & & & & & 25 & & & & 81,5 & \\
\hline Fusarium culmorum & 3 & 25 & 37 & 0 & 25 & 31 & 87 & & 90 & \\
\hline Fusarium oxysporum & & & & 5 & 30 & 37 & & & 90 & \\
\hline Fusarium solani & & & & & & & & & 90 & \\
\hline Trichoderma viride & & & & 0 & 28 & 37 & & & & 99 \\
\hline
\end{tabular}

Fonte: adaptado de Sedlbauer (2001).

O gênero Paecilomyces possui o crescimento do micélio a uma temperatura ótima de $35{ }^{\circ} \mathrm{C}$, contudo não há especificação das temperaturas mínimas para seu surgimento. A umidade relativa do ar para a germinação dos esporos é de $84 \%$. O gênero Cladosporium apresenta crescimento de micélio a uma temperatura mínima do ar de $-5{ }^{\circ} \mathrm{C}$, com umidade relativa do ar em torno dos $80 \%$. O gênero Fusarium, com uma temperatura do ar mínima de $3{ }^{\circ} \mathrm{C}$ e umidade relativa do ar próxima aos $90 \%$, apresenta germinação dos esporos.

\section{Definição das condições-limite e da transmitância térmica na parede externa da edificação}

A norma brasileira NBR 15575 (ABNT, 2008) indica o coeficiente global máximo permitido para a zona bioclimática 2 (Tabela 5).

Conforme mencionado anteriormente, para a presente análise foram aplicados os cálculos previstos em norma para determinação da transmitância térmica na edificação em estudo. Com base na definição da temperatura mínima para inverno, $12{ }^{\circ} \mathrm{C}$, em consonância com o projeto de norma 02:136.01.001: desempenho de edifícios habitacionais até 5 pavimentos: parte 1: requisitos gerais (ABNT, 2007) e a temperatura externa de 5 ${ }^{\circ} \mathrm{C}$ (COSTA, 1982), considerando-se um regime constante de troca de calor, foi calculada a transmitância térmica da parede externa, resultando em $\mathrm{U}=1,12 \mathrm{~W} / \mathrm{m}^{2}{ }^{\circ} \mathrm{C}$, atendendo, portanto, aos parâmetros apontados pela norma. Em seguida foram definidas as temperaturas superficiais internas da parede externa e do painel em madeira que compõem o ambiente (Figura 12).

$\mathrm{Rsi}=0,13 \mathrm{~m}^{2} \mathrm{~K} / \mathrm{W}$ (NBR 15575(ABNT, 2008)) a norma brasileira não possui valores específicos para diferentes situações;

$\mathrm{Rsi}=0,25 \mathrm{~m}^{2} \mathrm{~K} / \mathrm{W}$ (DIN 0418-3 (DEUTSCHES..., 2001)) - para ambientes aquecidos; e

$\mathrm{Rsi}=0,17 \mathrm{~m}^{2} \mathrm{~K} / \mathrm{W}$ (DIN 0418-3 (DEUTSCHES..., 2001)) - para ambientes não aquecidos.

Tabela 5 - Transmitância térmica para a zona bioclimática 2

\begin{tabular}{|c|c|c|c|}
\hline \multirow{3}{*}{ Nível de desempenho } & \multicolumn{3}{|c|}{$\mathrm{U}\left(\mathrm{W} / \mathrm{m}^{2}{ }^{\mathbf{o}} \mathrm{C}\right)$} \\
\hline & \multirow{2}{*}{ Zonas 1 e 2} & \multicolumn{2}{|c|}{ Zonas 3, 4, 5, 6, 7 e 8} \\
\hline & & $\alpha^{(2)}<0,6$ & $\alpha^{(2)} \geq 0,6$ \\
\hline M (mínimo) & $\mathrm{U} \leq \mathbf{2 , 5}$ & $\mathrm{U} \leq 3,7$ & $\mathrm{U} \leq 2,5$ \\
\hline \multicolumn{4}{|c|}{$\begin{array}{l}\text { Transmitância térmica com } \mathrm{R}_{\mathrm{Si}}=0,13 \mathrm{~m}^{2}{ }^{\circ} \mathrm{C} / \mathrm{W} \text { e } \mathrm{R}_{\mathrm{Se}}=0,04 \mathrm{~m}^{2}{ }^{\circ} \mathrm{C} / \mathrm{W} ;(2) \\
\text { Coeficiente de absorção }\end{array}$} \\
\hline
\end{tabular}

Fonte: adaptado da NBR 15575 (ABNT, 2008) e da NBR 15220-3 (ABNT, 2005). 


\section{Verificação da umidade relativa do ar nas proximidades da superfície interior da parede exterior}

As Tabelas 7 e 8 apresentam os valores encontrados para a umidade relativa próxima à parede, considerando 1 troca de ar por hora e 0,5 troca de ar por hora.

Para efeitos de cálculo foi considerado que uma pessoa libera $60 \mathrm{~g}$ de vapor d'água por hora (DIN 4108-3 (DEUTSCHES..., 2008)). Foi determinada uma média de 17 pessoas no ambiente, considerando uma pessoa para cada $3,00 \mathrm{~m}^{2}$ de área para galerias de arte (NBR 9077).

Observa-se, conforme os dados da Tabela 7, que, mesmo com uma taxa de 1,0 Ren/h, observa-se a probabilidade de surgimento do bolor para uma resistência superficial interna de 0,25 (ambientes aquecidos). Observando os dados da Tabela 8 , verifica-se que a influência da ventilação $(0,5$
Ren/h) gerou um aumento significativo da UR do ar próximo à superfície interna, resultando, para as três resistências superficiais consideradas, a possibilidade efetiva de formação do bolor.

\section{Determinação da temperatura e nível de umidade relativa do ar das superfícies do ambiente considerando- se um regime de transferência de calor transiente}

Para este trabalho, foi analisado apenas o ambiente da galeria de arte no térreo, e com a simulação foram obtidos os dados horários para o mês de junho. A partir daí, buscaram-se os dados de temperatura do ar e umidade do ambiente da galeria de arte, e calculou-se a umidade relativa próximo às superfícies desse ambiente. Os resultados podem se verificados nas Tabelas $9 \mathrm{e}$ 10 .

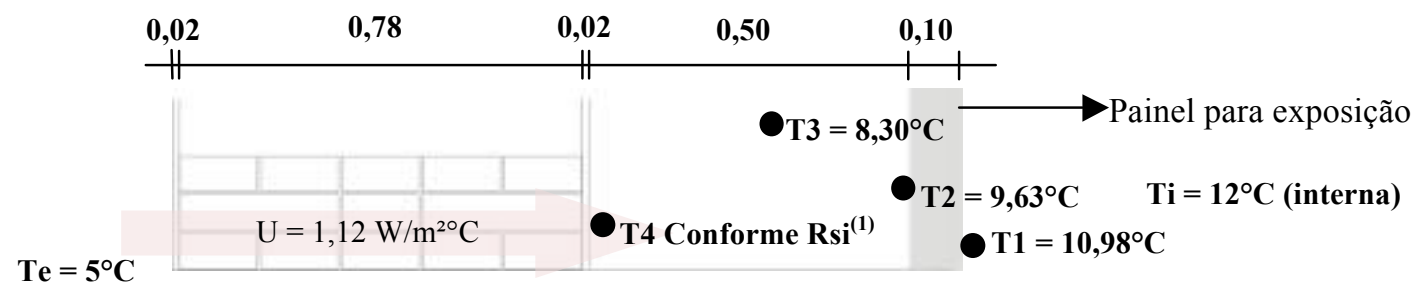

Figura 12 - Parede em corte - Pontos de temperaturas superficiais calculadas $\mathrm{U}=1,12 \mathrm{~W} / \mathrm{m}^{2}{ }^{\circ} \mathrm{C}$

(1) Para o cálculo da temperatura superficial da face interior da parede exterior foram propostas quatro diferentes condições para a resistência superficial interna (Tabela 5). Essas resistências foram definidas com base na norma brasileira NBR 15220-2 (ABNT, 2008a) e na norma alemão DIN 0418-03 (2001), descritas a seguir.

Tabela 6 - Temperatura superficial da face interior da parede exterior para as diferentes resistências superficiais internas

\begin{tabular}{|c|c|c|c|}
\hline $\begin{array}{l}\text { Temperatura da } \\
\text { face interior da } \\
\text { superfície exterior }\end{array}$ & $\begin{array}{c}\mathbf{R}_{\text {si }}=0,13 \mathrm{~m}^{2} \mathrm{~K} / \mathrm{W} \\
(\mathrm{NBR} 15220-2 \\
(\mathrm{ABNT}, 2008 \mathrm{a}))\end{array}$ & $\begin{array}{c}\mathbf{R}_{\text {si }}=0,25 \mathrm{~m}^{2} \mathrm{~K} / \mathrm{W} \\
(\mathrm{DIN} 4108-03) \\
\text { Ambientes } \\
\text { aquecidos }\end{array}$ & $\begin{array}{c}\mathbf{R}_{\text {si }}=0,17 \mathrm{~m}^{2} \mathrm{~K} / \mathrm{W} \\
(\mathrm{DIN} 4108-03) \\
\text { Ambientes não } \\
\text { aquecidos }\end{array}$ \\
\hline T4 & $7,28^{\circ} \mathrm{C}$ & $5,39^{\circ} \mathrm{C}$ & $6,63^{\circ} \mathrm{C}$ \\
\hline
\end{tabular}

Tabela 7 - Umidade relativa do ar próximo da superfície interior da parede exterior - 1,0 taxa de renovação do ar

\begin{tabular}{|c|c|c|c|c|c|c|c|c|c|c|c|c|c|}
\hline \multicolumn{14}{|c|}{ Galeria de arte - Casarão 2 - $U=1,12 \mathrm{~W} / \mathrm{m}^{2}{ }^{\circ} \mathrm{C}-1,0$ taxa de renovação do ar interior } \\
\hline \multirow{2}{*}{$\begin{array}{l}\text { Tempe- } \\
\text { ratura } \\
\text { interior }\end{array}$} & \multicolumn{2}{|c|}{$\begin{array}{c}\text { Umidade } \\
\text { relativa do } \\
\text { ar }\end{array}$} & \multicolumn{2}{|c|}{$\begin{array}{c}\text { Umidade } \\
\text { absoluta } \\
\text { do ar } \\
(\mathrm{g} / \mathrm{kg})\end{array}$} & \multicolumn{2}{|c|}{$\begin{array}{l}\text { Temperatu- } \\
\text { ra do ar }\end{array}$} & \multirow{2}{*}{$\begin{array}{l}\text { Ponto de } \\
\text { orvalho } \\
{ }^{\circ} \mathrm{C}\end{array}$} & \multicolumn{3}{|c|}{$\begin{array}{l}\text { Temperatura da superfície } \\
\left({ }^{\circ} \mathbf{C}\right)\end{array}$} & \multicolumn{3}{|c|}{$\begin{array}{l}\text { Umidade relativa do ar nas } \\
\text { proximidades da parede }(\%)\end{array}$} \\
\hline & $\begin{array}{l}\text { Int } \\
(\%)\end{array}$ & $\begin{array}{l}\text { Ext } \\
(\%)\end{array}$ & Int & Ext & $\begin{array}{l}\text { Int } \\
\left({ }^{\circ} \mathrm{C}\right)\end{array}$ & $\begin{array}{l}\text { Ext } \\
\left({ }^{\circ} \mathrm{C}\right)\end{array}$ & & $\begin{array}{c}\mathrm{Rsi}= \\
0,13 \mathrm{~m}^{2} \\
{ }^{\circ} \mathrm{C} / \mathrm{W}\end{array}$ & $\begin{array}{c}\mathrm{Rsi}= \\
0,25 \mathrm{~m}^{2} \\
{ }^{\circ} \mathrm{C} / \mathrm{W}\end{array}$ & $\begin{array}{c}\mathrm{Rsi}= \\
0,17 \mathrm{~m}^{2} \\
{ }^{\circ} \mathrm{C} / \mathrm{W}\end{array}$ & $\begin{array}{c}\text { Rsi }= \\
0,13 \mathrm{~m}^{2} \\
{ }^{\circ} \mathrm{C} / \mathrm{W}\end{array}$ & $\begin{array}{c}\mathrm{Rsi}= \\
0,25 \mathrm{~m}^{2} \\
{ }^{\circ} \mathrm{C} / \mathrm{W}\end{array}$ & $\begin{array}{c}\mathrm{Rsi}= \\
0,17 \mathrm{~m}^{2} \\
{ }^{\circ} \mathrm{C} / \mathrm{W}\end{array}$ \\
\hline
\end{tabular}

20 Guerra, F. L.; Cunha, E. G. da; Silva, A. C. S. B. da; Knop, S. 
Tabela 8 - Umidade relativa do ar próximo da superfície interior da parede exterior - 0,5 taxa de renovação do ar

\begin{tabular}{|c|c|c|c|c|c|c|c|c|c|c|c|c|c|}
\hline \multicolumn{14}{|c|}{ Galeria de arte - Casarão $2-\mathrm{U}=1,12 \mathrm{~W} / \mathrm{m}^{2}{ }^{\circ} \mathrm{C}-0,5$ taxa de renovação do ar interior } \\
\hline \multirow{2}{*}{$\begin{array}{l}\text { Tempe- } \\
\text { ratura } \\
\text { interior }\end{array}$} & \multicolumn{2}{|c|}{$\begin{array}{l}\text { Umidade } \\
\text { relativa } \\
\text { do ar }\end{array}$} & \multicolumn{2}{|c|}{$\begin{array}{c}\text { Umidade } \\
\text { absoluta do } \\
\operatorname{ar}(\mathrm{g} \mathrm{VA} / \mathrm{kg} \\
\text { AS) }\end{array}$} & \multicolumn{2}{|c|}{$\begin{array}{l}\text { Temperatura } \\
\text { do ar }\end{array}$} & \multirow{2}{*}{$\begin{array}{c}\text { Ponto de } \\
\text { orvalho } \\
{ }^{\circ} \mathrm{C}\end{array}$} & \multicolumn{3}{|c|}{$\begin{array}{l}\text { Temperatura da superfície } \\
\left({ }^{\circ} \mathrm{C}\right)\end{array}$} & \multicolumn{3}{|c|}{$\begin{array}{l}\text { Umidade relativa do ar nas } \\
\text { proximidades da parede }(\%)\end{array}$} \\
\hline & $\begin{array}{l}\text { Int } \\
(\%)\end{array}$ & $\begin{array}{l}\text { Ext } \\
(\%)\end{array}$ & Int & Ext & $\begin{array}{l}\text { Int } \\
\left({ }^{\circ} \mathrm{C}\right)\end{array}$ & $\begin{array}{l}\text { Ext } \\
\left({ }^{\circ} \mathrm{C}\right)\end{array}$ & & $\begin{array}{c}\mathrm{Rsi}= \\
0,13 \mathrm{~m}^{2} \\
{ }^{\circ} \mathrm{C} / \mathrm{W}\end{array}$ & $\begin{array}{c}\mathrm{Rsi}= \\
0,25 \mathrm{~m}^{2} \\
{ }^{\circ} \mathrm{C} / \mathrm{W}\end{array}$ & $\begin{array}{c}\mathrm{Rsi}= \\
0,17 \mathrm{~m}^{2} \\
{ }^{\circ} \mathrm{C} / \mathrm{W}\end{array}$ & $\begin{array}{c}\mathrm{Rsi}= \\
0,13 \mathrm{~m}^{2} \\
{ }^{\circ} \mathrm{C} / \mathrm{W}\end{array}$ & $\begin{array}{c}\mathrm{Rsi}= \\
0,25 \mathrm{~m}^{2} \\
{ }^{\circ} \mathrm{C} / \mathrm{W}\end{array}$ & $\begin{array}{c}\mathrm{Rsi}= \\
0,17 \mathrm{~m}^{2} \\
{ }^{\circ} \mathrm{C} / \mathrm{W}\end{array}$ \\
\hline $12{ }^{\circ} \mathrm{C}$ & 91 & 84 & 4,2 & 4,2 & 12 & 5 & 3,9 & 7,28 & 5,39 & 6,63 & 79,0 & 90,2 & 83,0 \\
\hline
\end{tabular}

Tabela 9 - Compilação dos resultados da simulação para o mês de junho

\begin{tabular}{|c|c|c|c|c|c|}
\hline $\begin{array}{c}\text { Situação } \\
\text { favorável com } \\
\text { temperatura } \\
>10^{\circ} \mathrm{C}\end{array}$ & $\begin{array}{c}\text { Frequência } \\
\qquad(\%)\end{array}$ & $\begin{array}{c}\text { Temperatura } \\
\text { média do ar } \\
\text { nas } \\
\text { ocorrências }\end{array}$ & $\begin{array}{l}\text { Temperatura } \\
\text { radiante (próx. a } \\
\text { paredes) média } \\
\text { nas ocorrências }\end{array}$ & $\begin{array}{l}\text { Temperatura } \\
\text { média mínima } \\
\text { do ar nas } \\
\text { ocorrências }\end{array}$ & $\begin{array}{c}\text { Temperatura } \\
\text { média } \\
\text { máxima do ar } \\
\text { nas } \\
\text { ocorrências }\end{array}$ \\
\hline $\begin{array}{l}\mathrm{UR}_{\text {próx. parede }}-< \\
60 \%\end{array}$ & $37 \%$ & $18,96{ }^{\circ} \mathrm{C}$ & $19,36^{\circ} \mathrm{C}$ & $15,88^{\circ} \mathrm{C}$ & $24,93{ }^{\circ} \mathrm{C}$ \\
\hline $\begin{array}{l}\text { UR próx. parede - } \\
60-70 \%\end{array}$ & $17,66 \%$ & $21,08^{\circ} \mathrm{C}$ & $20,57^{\circ} \mathrm{C}$ & $16,56^{\circ} \mathrm{C}$ & $28,19^{\circ} \mathrm{C}$ \\
\hline $\begin{array}{l}\text { UR próx. parede - } \\
70-80 \%\end{array}$ & $10,99 \%$ & $21,28^{\circ} \mathrm{C}$ & $19,89^{\circ} \mathrm{C}$ & $17,23{ }^{\circ} \mathrm{C}$ & $29,88^{\circ} \mathrm{C}$ \\
\hline $\begin{array}{l}\text { UR próx. parede - } \\
80-100 \%\end{array}$ & $25,17 \%$ & $21,28^{\circ} \mathrm{C}$ & $20,11^{\circ} \mathrm{C}$ & $20,17^{\circ} \mathrm{C}$ & $26,69^{\circ} \mathrm{C}$ \\
\hline $\begin{array}{l}\text { Condensação - } \\
\text { UR próx. parede = } \\
100 \%\end{array}$ & $9,18 \%$ & $23,50^{\circ} \mathrm{C}$ & $21,72^{\circ} \mathrm{C}$ & $22,69^{\circ} \mathrm{C}$ & $24,53{ }^{\circ} \mathrm{C}$ \\
\hline
\end{tabular}

Tabela 10 - Ocorrência de UR acima dos $80 \%$

\begin{tabular}{l|c}
\hline \multicolumn{1}{c|}{ Período de UR $>\mathbf{8 0} \%$} & Número de ocorrências \\
\hline 6 h seguidas & 30 \\
\hline 12 h seguidas & 10 \\
\hline 24 h seguidas & 4 \\
\hline
\end{tabular}

Diferentemente da análise do processo de transferência de calor estacionário, em que a análise foi feita para uma superfície, no caso da simulação, trabalhou-se com a temperatura média radiante, ou seja, a temperatura média das superfícies do ambiente para o período de 1 mês, considerando junho como o período mais crítico, em razão de apresentar as menores temperaturas médias do ano.

A Tabela 9 caracteriza que em cerca de $45 \%$ do tempo a umidade relativa esteve acima dos $70 \%$. Também foi possível observar, conforme a Tabela 10, que houve cerca de 30 ocorrências da umidade relativa acima de $80 \%$ por um período mínimo de $6 \mathrm{~h}$, o que também confirma a possibilidade de surgimento do bolor.

\section{Conclusões}

Os resultados das análises desenvolvidas neste trabalho puderam demonstrar que, tanto no caso da análise das temperaturas superficiais das paredes externas considerando-se o regime de transferência de calor estacionário, quanto para o regime de transferência de calor transiente, observando os fatores umidade relativa do ar e temperatura superficial da parede, há a possibilidade concreta de formação de bolor. Portanto, mesmo no caso dessa edificação, onde se observou um baixo valor de transmitância e alta capacidade térmica, verificaram-se valores de temperaturas superficiais internas baixos com altos índices de umidade relativa do ar, o que torna o microclima favorável ao desenvolvimento do bolor. 
É válido ressaltar que os valores obtidos para os dois métodos adotados na verificação, em relação à umidade relativa do ar e temperatura superficial, para os gêneros de fungos identificados, estão presentes na faixa das condições limites tomadas como referência para este trabalho, o que reforça a probabilidade da ocorrência desses agentes microbiológicos, responsáveis pelo desenvolvimento do bolor.

É possível verificar também que, para o contexto analisado, torna-se necessária a climatização artificial, a fim de equilibrar os níveis de umidade relativa do ar e a temperatura superficial interna, de forma a controlar o microclima do ambiente e, por consequência, conter o desenvolvimento do bolor. Outro aspecto interessante a ser destacado é a forma como está sendo utilizado o ambiente. A aplicação dos painéis em frente às esquadrias, associada ao fato de estas serem abertas com pouca frequência, devido à dificuldade de acesso, possivelmente está prejudicando os níveis de renovação do ar por meio da ventilação natural, o que pode estar agravando o dano detectado. No momento em que foi desenvolvido este estudo ainda não havia sido aprovada a nova versão da NBR 15575 (ABNT, 2008): desempenho das edificações, portanto, conforme mencionado anteriormente, foi adotada a temperatura interior mínima para inverno de $12{ }^{\circ} \mathrm{C}$. Destaca-se que a atual versão da norma considera como referência a temperatura exterior, aceitando medidas internas iguais ou superiores às externas. Dessa forma, demonstra-se importante o desenvolvimento de estudos acerca do desempenho mínimo satisfatório para as edificações, pois, além de permitir condições pouco favoráveis do ponto de vista do conforto térmico ambiental, não faz menção a valores-limites de temperatura para as superfícies internas das edificações, de forma a adequar o ambiente com vistas a impedir o surgimento e proliferação do bolor. A exemplo da norma alemã, DIN 4108-3 (DEUTSCHES..., 2008), é possível apontar valores de temperatura superficial e umidade relativa próximos à parede com o objetivo de conter a ação dos fungos causadores do problema.

Este trabalho buscou também destacar a importância do desenvolvimento de estudos que compreendam os fatores responsáveis pelo surgimento do bolor, enfatizando a importância dos danos por este ocasionados, principalmente nas edificações históricas.

\section{Referências}

ALLSOPP, D.; SEAL, K.; GAYLARDE, C. Introduction to Biodeterioration. $2^{\mathrm{TH} .} \mathrm{New}$ York: Cambridge University Press, 2010.

ASSOCIAÇÃO BRASILEIRA DE NORMAS TÉCNICAS. NBR 15575: edifícios habitacionais de até cinco pavimentos. Rio de Janeiro, 2008.

ASSOCIAÇÃO BRASILEIRA DE NORMAS TÉCNICAS. NBR 9070: saídas de emergência em edifícios. Rio de janeiro, 2001.

ASSOCIAÇÃO BRASILEIRA DE NORMAS

TÉCNICAS. NBR 15220-2: desempenho térmico de edificações: parte 2: método de cálculo de transmitância térmica, da capacidade térmica, do atraso térmico e do fator solar de elementos e componentes de edificações. Rio de Janeiro, 2008.

\section{ASSOCIAÇÃO BRASILEIRA DE NORMAS}

TÉCNICAS. NBR 15220-3: desempenho térmico de edificações: parte 3: zoneamento bioclimático brasileiro e diretrizes construtivas para habitações unifamiliares de interesse social. Rio de Janeiro, 2005.

\section{ASSOCIAÇÃO BRASILEIRA DE NORMAS}

TÉCNICAS. NBR 15575: edifícios habitacionais de até cinco pavimentos. Rio de Janeiro, 2008.

BREYMANN, G. A. Trattato di Costruzioni Civili. Archi - Volte - Cupole [1885]. 5 ed. Tradução Carlo Valentini. Roma: Editrice Librerie Dedalo, 2003. 182 p.

CANEVA, G.; NUGARI, M. P.; SALVADORI, O. La Biología en la Restauración. Traducción de Rosalía Gómez. Sevilla: Nerea, 2000.

\section{COSTA, E. Arquitetura Ecológica:}

condicionamento térmico natural. São Paulo: Edgard Blucher, 1982.

CUNHA, E. G.; FRITSCH, R. C. Verificação de Mofo e Bolor em Superfícies Interiores de Paredes Exteriores Situadas na Zona Bioclimática 3 de Acordo Com a NBR 15220 e NBR 15575. In: ENCONTRO NACIONAL, 10.; ENCONTRO LATINO AMERICANO DE CONFORTO NO AMBIENTE CONSTRUÍDO, 6., Natal, 2009. Anais... Natal: ENTAC, 2009. 1 CD-ROM.

DESIGNBUILDER. Software. Versão 3.0.0.064. 2011.

DEUTSCHES INSTITUT FÜR NORMUNG. DIN 4108-2: Wärmeschutz und Energie-Einsparung in Gebäuden. Teil 2: Mindestanforderungen an der Wärmeschutz. Berlin, 2003. 
DEUTSCHES INSTITUT FÜR NORMUNG. DIN 4108-3: Wärmeschutz und Energie-Einsparung in Gebäuden. Teil 3: Klimabedingter Feuchteschutz, Anforderungen, Berechnungsverfahren und Hinweise für Planung und Ausführung. Berlin, 2001.

EMPRESA BRASILEIRA DE PESQUISA AGROPECUÁRIA. Normais Climatológicas: estacional. Disponível em:

$<$ http://www.cpact.embrapa.br/agromet/estacao/est acional.html>. Acesso em: janeiro de 2011.

\section{ENVIRONMENTAL CONTRATING}

RESTORATION. Fact Sheets: introduction to Fungi (Mold). Disponível em:

$<$ http://www.ecometrex.com/mold_introduction.ht m>. Acesso em: 20 dez. 2012.

MARTINS, D. J. et al. Ensaio Sobre a Utilização da Automação de Aberturas na Simulação do Desempenho Térmico de Edificações. In: ENCONTRO NACIONAL10; ENCONTRO LATINO AMERICANO DE CONFORTO NO AMBIENTE CONSTRUÍDO, 6., Natal, 2009. Anais... Natal: ENTAC, 2009. 1 CD-ROM.

NASCIMENTO, C. B.; CINCOTTO, M. A. Influência do Ataque Fúngico de Ripas de Juçara em Argamassa de Estuque: estudo de caso. São Paulo: EPUSP, 2003. Disponível em: $<$ http://publicacoes.pcc.usp.br/PDF/BTs_Petreche/ BT348-\%20Nascimento.PDF $>$. Acesso em: 5 jan. 2011.

PERES, Rosilena. Legado da Tecnologia Construtiva de Construtores Italianos ao Patrimônio Arquitetônico de Pelotas. $300 \mathrm{f}$. Porto Alegre, 2008. Tese (Doutorado em Engenharia Civil) - Escola de Engenharia, Universidade Federal do Rio Grande do Sul, Porto Alegre, 2008.

\section{SECRETARIA MUNICIPAL DE CULTURA PELOTAS. Programa de Recuperação do} Centro Histórico de Pelotas. Pelotas: SCULT, 2002.

\section{SEDLBAUER, K. Prediction of Mould Fungus Formation on the Surface of and Inside Building Components. Holzkirchen: Fraunhofer Institute for Building Physics, 2001.}

DO, E. Ventilação Natural das Habitações. Maceió: Edufal, 1999.

\section{Agradecimentos}

Ao arquiteto e urbanista Fábio Caetano, da Secretaria Municipal de Cultura de Pelotas, e demais funcionários, pela colaboração e acesso ao Casarão 2, estudado neste trabalho.

Ao professor engenheiro civil Sérgio Lund Azevedo, da Faculdade de Arquitetura e Urbanismo da Universidade Federal de Pelotas, pela orientação no desenvolvimento da análise de materiais.

Ao professor biólogo Eduardo Bernardi, do Instituto de Biologia da Universidade Federal de Pelotas, pela orientação e auxílio no desenvolvimento das análises microbiológicas.

Ao laboratorista Rogério Falcão e à técnica estagiária Bruna Silva da Cruz, do Laboratório de Materiais de Construção e Solos do Instituto Federal Sul-Rio-Grandense (IFSul-Pelotas/RS), pela orientação e disponibilidade de acesso ao laboratório.

Revista Ambiente Construído

Associação Nacional de Tecnologia do Ambiente Construído

Av. Osvaldo Aranha, $99-3^{\circ}$ andar, Centro

Porto Alegre - RS - Brasil

CEP $90035-190$

Telefone: +55 (51) 3308-4084

Fax: +55 (51) 3308-4054

www.seer.ufrgs.br/ambienteconstruido

E-mail: ambienteconstruido@ufrgs.br 